\title{
Temporal and spatial distributions of marine Synechococcus in the Southern California Bight assessed by hybridization to bead-arrays
}

\author{
Vera Tai ${ }^{1,2}$, Ronald S. Burton ${ }^{1}$, Brian Palenik ${ }^{1, *}$ \\ ${ }^{1}$ Marine Biology Research Division, Scripps Institution of Oceanography, University of California San Diego, \\ 9500 Gilman Drive, La Jolla, California 92093, USA \\ ${ }^{2}$ Present address: Department of Botany, University of British Columbia, 3529-6270 University Boulevard, Vancouver, \\ British Columbia V6T 1Z4, Canada
}

\begin{abstract}
Marine Synechococcus diversity has been previously described using multi-locus gene sequence phylogenies and the identification of distinct clades. Synechococcus from Clades I, II, III, and IV and from sub-clades within Clades I and IV were enumerated from environmental samples by developing a hybridization assay to liquid bead-arrays (Luminex). Oligonucleotide probes targeting a gene encoding a subunit of RNA polymerase ( $r p o C 1)$ were used simultaneously in multiplexed assays to track Synechococcus diversity from a Pacific Ocean coastal monitoring site and along a coastal to open-ocean transect in the Southern California Bight. The Luminex assay demonstrated that Synechococcus from Clades I and IV were the dominant types at the coastal site throughout the year. Synechococcus from Clades II and III were not detected except during the late summer or early winter. Within the dominant Clades I and IV, rpoC1-defined sub-clades of Synechococcus showed distinct spatial distributions along the coastal to open-ocean transect, coinciding with changes in the nitricline, thermocline, and fluorescence (chlorophyll) maximum depths. In coastal waters, Synechococcus targeted by 2 sub-clade IV probes were dominant at the surface, whereas 2 sub-clade I probes and a third sub-clade IV probe had increased signals in deeper water near the fluorescence maximum. In mesotrophic waters, this third sub-clade IV probe dominated at the fluorescence maximum (depth of 50 to $70 \mathrm{~m}$ ), whereas all other sub-clade probes were below detection limits. The differing distributions of sub-clades within the dominant Synechococcus clades indicate that the subclades likely have adapted to distinct ecological niches found within the Southern California Bight.
\end{abstract}

KEY WORDS: Cyanobacteria $\cdot$ Microbial ecology $\cdot$ Biogeography $\cdot$ Time-series $\cdot$ Luminex

\section{INTRODUCTION}

Marine Synechococcus are the dominant cyanobacteria in coastal environments and are found throughout the world's oceans (Johnson \& Sieburth 1979, Waterbury et al. 1979). They are important contributors to primary production and are also very diverse. At least 10 different clades of Synechococcus have been identified based on phylogenetic markers such as the RNA polymerase gene, small subunit ribosomal RNA gene, and internal transcribed spacer region (Ferris \& Palenik 1998, Rocap et al. 2002, Fuller et al. 2003).
However, little is known about the physiological and ecological characteristics that distinguish each clade of Synechococcus and the abundance and distribution of these clades, or that tell how these factors might affect rates of primary production or other biogeochemical cycles.

Synechococcus Clades I, II, and IV are the most common throughout the world's oceans (Zwirglmaier et al. 2008). Clades I and IV typically dominate temperate coastal environments (Brown \& Fuhrman 2005, Zwirglmaier et al. 2008, Tai \& Palenik 2009), while Clade II is found in subtropical or tropical environments (Fuller et 
al. 2006, Zwirglmaier et al. 2008) and off-shore oligotrophic environments (Ferris \& Palenik 1998, Toledo \& Palenik 2003, Ahlgren \& Rocap 2006). Physiologically, differences in growth rates, in nitrogen and phosphate utilization, in pigment composition, in chromatic adaptation, and in motility have typically been used to describe isolated strains of Synechococcus (Moore et al. 1995, 2005, Collier et al. 1999, Toledo et al. 1999, Ahlgren \& Rocap 2006), but, with the exception of motility (which has been found only in Clade III isolates), phenotypic traits and adaptations that uniquely characterize the genetically defined clades have yet to be identified.

To understand the ecology of Synechococcus, diversity and abundance measures are fundamental. However, due to their small size, obtaining these measures is technically challenging. Traditionally, microbes are often distinguished physiologically by studying cultured isolates. But since only a small fraction of microbial diversity is represented by cultured isolates, and since the process of cultivation is labor-intensive, culture-independent and molecular methods have become the primary means to investigate microbial diversity (Fuhrman et al. 2002, Nocker et al. 2007).

Marine Synechococcus biogeography has been examined using clade-specific probes for Southern hybridizations (Fuller et al. 2006, Zwirglmaier et al. 2007, 2008) and for serotyping (Campbell \& Carpenter 1987, Toledo \& Palenik 2003). A more precise measure of abundance using quantitative polymerase chain reaction (qPCR) has also been developed for marine Synechococcus clades (Tai \& Palenik 2009). In addition, sequencing and fingerprinting of a marker gene (often the 16S ribosomal RNA gene) are among the most common ways to describe or document changes in microbial diversity (e.g. Fuhrman et al. 2006, Muhling et al. 2006, Huber et al. 2007). In particular, DNA sequences from cultured isolates and environmental libraries of a gene encoding a subunit of the RNA polymerase (rpoC1) have demonstrated the diversity of Synechococcus within the Southern California Bight (Toledo \& Palenik 1997, Ferris \& Palenik 1998, Toledo et al. 1999). While these methods have provided a wealth of information concerning microbial ecology and evolution, there is a need to develop faster, less expensive, but quantitative means to interrogate microbial diversity.

The present study investigates the use of liquid bead-array technology implemented on a Luminex100 instrument (Luminex) to assess the diversity and abundance of marine Synechococcus. The bead-array assay is based on DNA hybridization to oligonucleotide probes coupled to beads, followed by flow cytometric quantification of hybridization. This technology is designed for rapid, high-throughput, cus- tomizable, multiplex investigations. Luminex beadarrays have been developed for detecting microbial pathogens from clinical (e.g. Bandyopadhyay et al. 2007) and environmental (Baums et al. 2007) samples. Applications of this technology have also been used to determine bacteria and phytoplankton abundances from the marine environment (Ellison \& Burton 2005, Scorzetti et al. 2009, Mayali et al. 2010).

For the present study, we developed probes for bead-array assays based on rpoC1 gene sequences. We did this to assess changes in the diversity and abundance of marine Synechococcus from a 1 yr timeseries of coastal samples and along a coastal to openocean transect from the Southern California Bight in the northeastern Pacific Ocean. We were able to analyze several probes and samples in a single assay, making it possible to rapidly examine microscale diversity patterns of Synechococcus biogeography.

\section{MATERIALS AND METHODS}

Environmental samples. Microorganisms were collected from surface waters at the end of the Scripps Institution of Oceanography (SIO) pier, La Jolla, California, USA, located at the southern end of the Southern California Bight $\left(32.8672^{\circ} \mathrm{N}, 117.2583^{\circ} \mathrm{W}\right)$. As previously described (Tai \& Palenik 2009), seawater samples $(0.5$ or $1 \mathrm{l})$ were filtered onto $0.2 \mu \mathrm{m}$ Supor filter discs (Pall Life Sciences) for DNA extraction, and $1 \mathrm{ml}$ samples were preserved in $0.25 \%$ gluteraldehyde (Sigma-Aldrich) to determine total Synechococcus abundances, by flow cytometry. Samples taken at approximately monthly intervals from 5 January 2006 to 26 February 2007 were analyzed for the present study. Samples from the pier had also been obtained on 28 February 2001, 9 May 2001, 11 July 2001, and 30 August, 2001, as well as samples from the chlorophyll maximum $(28.5 \mathrm{~m})$ off-shore of Mission Beach, San Diego, CA $\left(32.7694^{\circ} \mathrm{N}\right.$, $117.4032^{\circ} \mathrm{W}$ ) on 11 August 2006 for use in rpoC1 clone libraries.

In addition to the aforementioned samples, we collected samples from 10 stations along a coastal to openocean transect from 17 July to 4 August 2007 for DNA extractions and flow cytometry analysis. The transect was colinear with Line 93.3 of the California Cooperative Oceanic Fisheries Investigations (CalCOFI) sampling grid in the Southern California Bight (from $32.9564^{\circ} \mathrm{N}, 117.3054^{\circ} \mathrm{W}$ to $29.8464^{\circ} \mathrm{N}, 123.5866^{\circ} \mathrm{W}$ ). Samples were taken at discrete depths through the euphotic zone using a conductivity-temperature-depth profiler (CTD) rosette from Stns 26, 35, 40, 45, 50, 80, 90, 110, and 120 (station coordinates may be found at www.calcofi.org) (Fig. 1). The stations are designated 


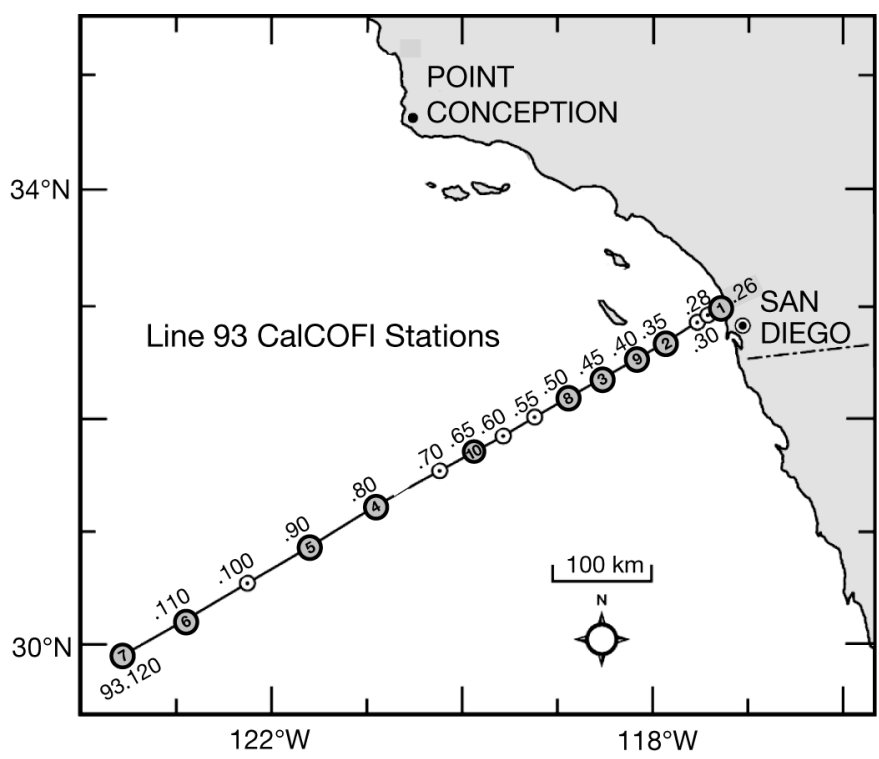

Fig. 1. Location of stations sampled along a coastal to openocean transect. The transect was along Line 93 of the CalCOFI sampling grid. Stations sampled are colored in grey and numbered in the order that they were sampled. Station 93.65 is not part of the CalCOFI sampling grid, but was sampled for this transect

by the line number, a period, then the station (e.g. 93.26 = Line 93.3, Stn 26). An additional station (Stn 65, $31.6776^{\circ} \mathrm{N}, 119.9025^{\circ} \mathrm{W}$ ) sampled was not part of the CalCOFI sampling grid.

At each station, total Synechococcus abundances were determined by flow cytometry analysis from the samples of the depth profile, and the depth of maximum Synechococcus abundance was identified. For the bead-array assay, samples from the surface, the Synechococcus abundance maxima, and the fluores- cence maxima (a proxy for the chlorophyll maxima as determined from a fluorometer mounted to the CTD rosette used for sample collection) were analyzed, with a few exceptions (Table 1). At Stns 93.26, 93.40, and 93.65, the depth of the Synechococcus and fluorescence maxima coincided, but for all other stations, the Synechococcus maxima were above the fluorescence maxima.

Strains used as Luminex standards. Synechococcus strains used as standards were grown in artificial seawater as previously described (Su et al. 2006) with $9.0 \mathrm{mmol} \mathrm{l}^{-1} \mathrm{NaNO}_{3}$. Vitamins $\left(0.2 \mathrm{mg} \mathrm{l}^{-1}\right.$ thiamin- $\mathrm{HCl}$, $1 \mu \mathrm{g}^{-1}$ d-biotin, and $1 \mu \mathrm{g} \mathrm{l}^{-1} \mathrm{~B}_{12}$ ) were also added. Strains representing 4 different clades of Synechococcus were used: Synechococcus sp. CC9311 (Clade I), Synechococcus sp. CC9605 (Clade II), Synechococcus sp. WH8102 (Clade III), and Synechococcus sp. CC9902 (Clade IV). Batch cultures were grown in glass flasks, gently stirred, at $25^{\circ} \mathrm{C}$ under $30 \mu \mathrm{mol}$ quanta continuous white light. Cells were harvested by filtration onto $0.2 \mu \mathrm{m}$ Supor filter discs and stored at $-20^{\circ} \mathrm{C}$.

DNA extraction. Genomic DNA from cultured strains and environmental samples were extracted as previously described (Tai \& Palenik 2009). Briefly, lysozyme (Sigma), Proteinase K (Sigma), and sodium dodecyl sulphate (SDS) (BioRad) were used to lyse cells collected on a $0.2 \mu \mathrm{m}$ Supor filter disc. Phenol:chloroform ratio extractions were used to isolate the DNA from lipids and proteins, and the DNA was cleaned using the DNeasy Blood and Tissue kit (Qiagen).

rpoC1 environmental clone libraries. $R p o C 1$ clones were obtained by PCR amplification of environmental DNA, ligation into a plasmid vector, and transformation into competent Escherichia coli as described in Tai \& Palenik (2009). To prepare plasmid DNA of rpoC1

Table 1. Sample stations and depths analyzed using Synechococcus sub-clade probes along a coastal to open-ocean transect. na $=$ not available

\begin{tabular}{|c|c|c|c|c|c|c|c|}
\hline Station & $\begin{array}{l}\text { Distance from } \\
\text { shore }(\mathrm{km})\end{array}$ & $\begin{array}{c}\text { Surface } \\
\text { sample }(\mathrm{m})\end{array}$ & $\begin{array}{l}\text { Synechococcus max- } \\
\text { imum sample (m) }\end{array}$ & $\begin{array}{l}\text { Fluorescence max- } \\
\text { imum sample (m) }\end{array}$ & $\begin{array}{l}\text { Thermocline } \\
\text { depth }(\mathrm{m})\end{array}$ & $\begin{array}{l}\text { Nitricline } \\
\text { depth }(\mathrm{m})\end{array}$ & $\begin{array}{c}\text { Estimated bottom } \\
\text { depth (m) }\end{array}$ \\
\hline 93.26 & 10.8 & 3 & 18 & 18 & 15 & 18 & 63 \\
\hline 93.35 & 61.1 & 5 & 20 & $-^{\mathrm{a}}$ & 17 & 33 & 616 \\
\hline 93.40 & 97.6 & 5 & 30 & 30 & 20 & 45 & 1627 \\
\hline 93.45 & 134.4 & 5 & 20 & 40 & 23 & 30 & 1326 \\
\hline 93.50 & 171.2 & 5 & 15 & 30 & 35 & 35 & 1452 \\
\hline 93.65 & 281.9 & 5 & 30 & 30 & 30 & 30 & na \\
\hline 93.80 & 392.6 & 5 & 40 & 70 & 60 & 100 & 3848 \\
\hline 93.90 & 466.4 & 10 & 43 & 53 & 60 & 120 & 4109 \\
\hline 93.110 & 614.0 & 5 & 50 & $100^{\mathrm{b}}$ & 120 & 180 & 4017 \\
\hline 93.120 & 687.8 & 10 & 50 & $90^{\mathrm{C}}$ & 120 & 180 & 4061 \\
\hline
\end{tabular}


clones, the QIAprep kit (Qiagen) was used following the manufacturer's protocol. Sequence data from Synechococcus rpoC1 clones are reported here. These sequences were aligned with data from previous environmental libraries and Synechococcus strains to calculate phylogenetic trees. These trees were used to design sub-clade probes and to choose clones to use as hybridization standards (see 'Probe design').

Developing the bead-array assay. To evaluate Synechococcus diversity, the rpoC1 gene was used as the phylogenetic marker. Clade-specific and sub-clade oligonucleotide probes were designed to hybridize to a variable region within the $r p o C 1$ gene sequence. For use in the bead-array assay, the probes were coupled to fluorescent microspheres. A fragment of the rpoC1 gene including the probe region was amplified from environmental samples by PCR using primers specific to marine Synechococcus. One of the primers was biotinylated, thereby generating biotinylated amplicons. Hybridization conditions were established using PCR amplicons from DNA of cultured isolates or environmental clones prior to examining environmental samples. The development of the assay involved varying the probe sequence, the size of the biotinylated PCR product, the PCR conditions, and the hybridization temperature, time, and wash steps. The methods that produced optimal results are described in the following sections.

Probe design. Two sets of probes were used in beadarray assays, one set to target Synechococcus at the clade level and another to target sub-clades within Synechococcus Clades I and IV. Probes were designed to hybridize to a variable region (nucleotides 604 to 624 from the start of the rpoC1 gene) within the 547 base-pair (bp) rpoC1 fragment amplified by PCR, as described below. The probe sequences, which were designed to be complementary to the biotinylated strand amplified by PCR, contained an amine-12 carbon linker on the $5^{\prime}$ end for coupling to the carboxylated Luminex beads (Bioneer). Care was taken to include mismatches near the middle of the probe, as this enhances hybridization specificity.

For the clade probe set, to avoid using degenerate oligonucleotides, 4 probes were designed to exactly match the rpoC1 variable region of cultured strains representing Clades I, II, III, and IV (Table 2). In all cases, the probe sequence was specifically targeted at the most commonly strain within each clade, based on environmental clone libraries of rpoC1 gene sequences. Not all Synechococcus belonging to a clade were probed, however, as it was not possible to design a probe that encompassed all known diversity.

Sub-clade probes were designed based on a phylogenetic tree calculated using Neighbor-joining from a $460 \mathrm{bp}$ alignment of all available Synechococcus
Table 2. Oligonucleotide probes used in the Luminex assay. Probes I-A and IV-A are common to both sets, but were used at different hybridization temperatures. The clade probe set was used at a hybridization temperature of $55^{\circ} \mathrm{C}$ and the subclade probe set at $58^{\circ} \mathrm{C}$. Nucleotides that differ between the strain-specific probes are in bold upper case. Nucleotides that differentiate the sub-clade probes are in bold lower case

\begin{tabular}{|lll|}
\hline Probe & Strain & Sequence $\left(5^{\prime}\right.$ to $3^{\prime}$ ) \\
\hline Clade probe set & \\
I-A & CC9311 & AGC ATT GAG TTG GAG ATC CTC \\
II & CC9605 & TTC ATC GAG GGT AAG ATC TTC \\
III & WH8102 & TTC CTC CAG ATT GAG GTC TTC \\
IV-A & CC9902 & TTC TTC AAG GCT GAG ATC CTC \\
Sub-clade probe set \\
I-A & CC9311 & AGC ATT GAG TTG GAG ATC CTC \\
I-B & & AGC ATT GAG TTG aAG ATC CTC \\
I-C & & AGC gTT GAG TTG GAG gTC tTC \\
I-D & & AGC gTT GAG TTG aAG gTC tTC \\
I-E & & AGC ATT GAG TTG aAG ATC tTC \\
IV-A & CC9902 & TTC TTC AAG GCT GAG ATC CTC \\
IV-B & & cTC gTt AAG GCT GAG ATC CTg \\
IV-C & & CGC GAC TTC cTC AAG GCT GAG \\
\hline
\end{tabular}

rpoC1 sequences (PAUP* ${ }^{*}$ 4.10b). Neighbor-joining trees were recalculated with statistical support from 1000 bootstrap replicates for all Synechococcus sequences belonging to Clade I (Fig. 2a) and Clade IV (Fig. 2b). These Clade I and IV sequences were examined for variability within the probing region. If 3 or more environmental clones were found for this specific probe sequence, a sub-clade probe was designed. This resulted in 4 Clade I probes, in addition to the one specific to strain CC9311, and 2 Clade IV probes, in addition to the one specific to strain CC9902 (Table 2). For probe IV-C, the probe was shifted 6 nucleotides towards the $5^{\prime}$ end to enhance hybridization specificity. The rpoC1 sequences targeted by these sub-clade probes generally clustered phylogenetically (Fig. 2).

Probe coupling to beads. Probes were coupled to carboxylated Microplex microspheres (Luminex, MiraiBio), referred to here as beads, following the procedure of Yang et al. (2001), except using $0.2 \mathrm{nmol}$ of oligonucleotide probe. Each probe was coupled to a different stock of beads that were identified by a unique fluorescent color. The coupled beads (beadprobes) were stored in $10 \mathrm{mmol} \mathrm{l}^{-1}$ Tris and $1 \mathrm{mmol} \mathrm{l}^{-1}$ EDTA, pH 8.0, at $4^{\circ} \mathrm{C}$ in the dark.

Generating biotinylated Synechococcus rpoC1 gene fragments. Synechococcus-specific PCR primers that flank a variable region of the rpoC1 gene were designed (RPOC493F: 5'-biotin-CTN ACN GAR GAY GAR TGG YT-3'; SAC-1039R: 5'-CYT GYT TNC CYT CDA TDA TRT C-3'; Bioneer, Integrated DNA Technologies). RPOC493F was biotinylated on the 5 ' end for detection using streptavidin-phycoerythrin (strep-PE) 


\section{a Clade I}

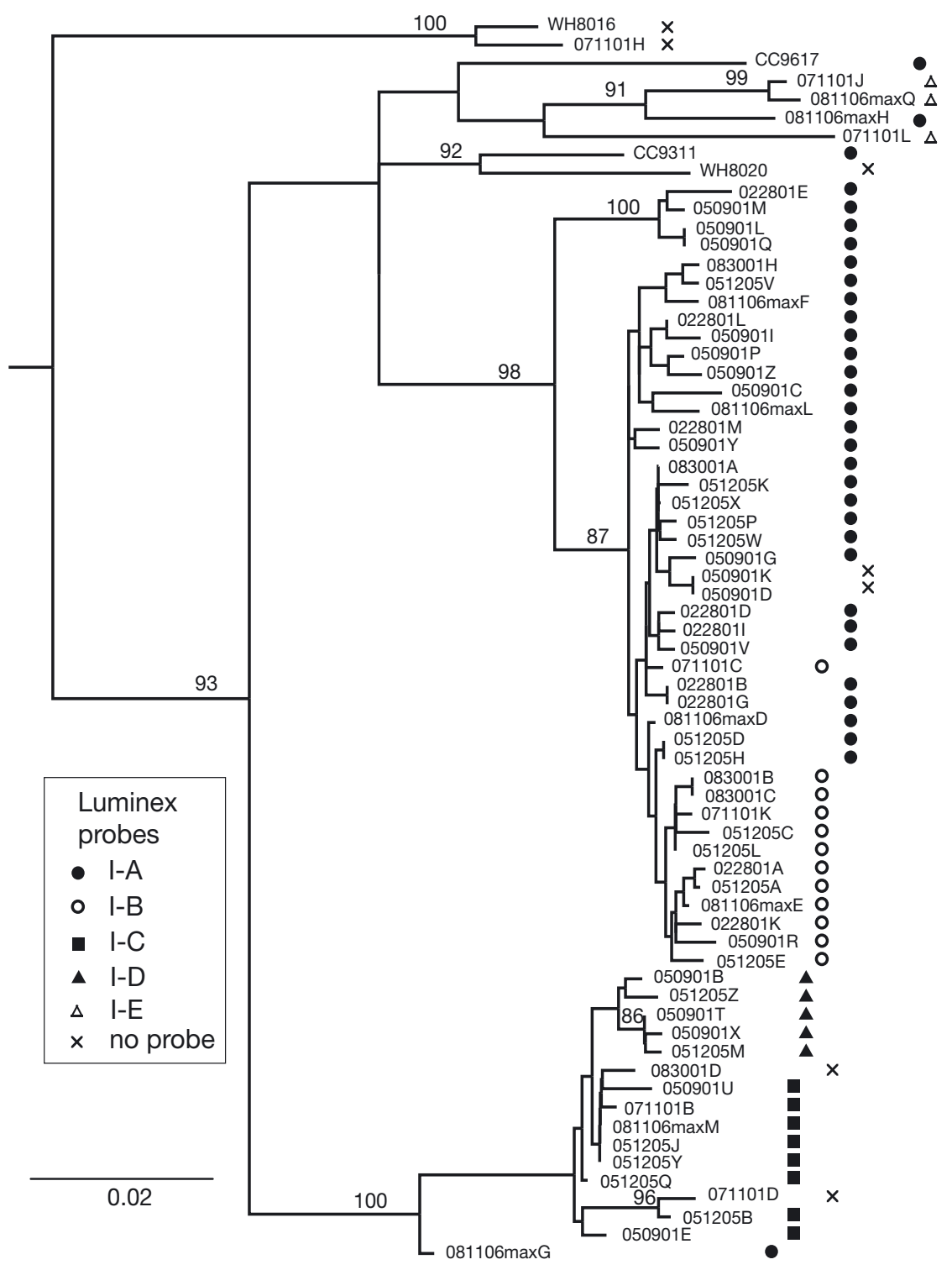

b Clade IV

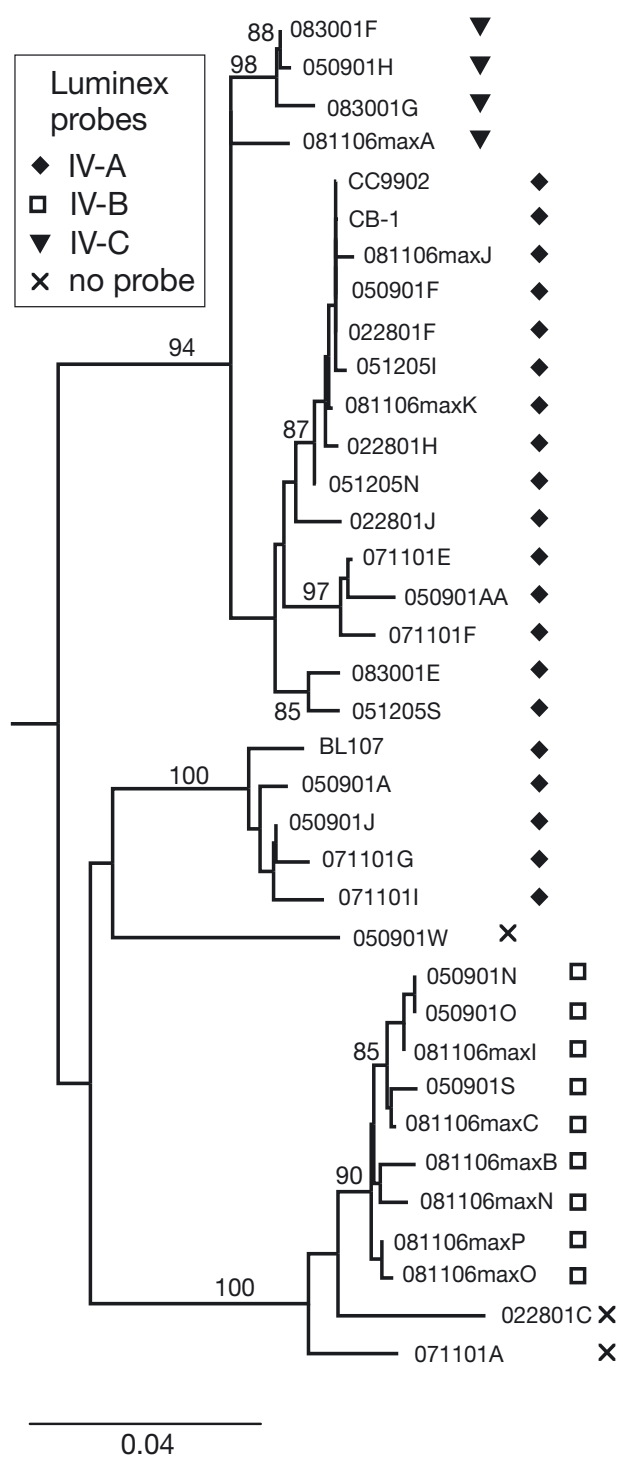

Fig. 2. Neighbor-joining tree of rpoC1 sequences belonging to Synechococcus from (a) Clade I and (b) Clade IV. The Luminex sub-clade probe that targets each sequence is denoted by a symbol next to the sequence name. Bootstrap values are shown on branches with $85 \%$ or greater support. The Clade I and Clade IV trees were rooted with the CC9902 and CC9311 rpoC1 sequences, respectively. Sequences from rpoC1 environmental libraries of surface waters collected from the end of the Scripps Institution of Oceanography (SIO) pier are labeled with the date of sample collection (mmddyy) followed by a letter to designate the environmental clone. 051205 sequences are from Tai \& Palenik (2009). 081106max sequences are from an environmental rpoC1 library sampled from the chlorophyll maximum (28.5 m depth) $15 \mathrm{~km}$ off-shore of Mission Beach, San Diego, CA $\left(32.7694^{\circ} \mathrm{N}, 117.4032^{\circ} \mathrm{W}\right)$ (Lucas et al. 2011). CB-1 is a cultured strain isolated from surface waters at the end of the SIO pier in 1999. All other sequences are from strains with previously published isolation details (Toledo \& Palenik 1997, Toledo et al. 1999, Palenik 2001, Rocap et al. 2002, Dufresne et al. 2008). All sequences not previously available in GenBank (www.ncbi.nlm. nih.gov/Genbank) have been submitted (accession numbers GU990533-GU990611)

(Invitrogen) following hybridization to the Luminex beads. The PCR consisted of $25 \mu$ of Platinum ${ }^{\circledR}$ PCR SuperMix (Invitrogen), 200 pmol each of RPOC493F and SAC-1039R, and template DNA. The reaction was heated to $94^{\circ} \mathrm{C}$ for $2 \mathrm{~min}$, followed by 35 cycles of $94^{\circ} \mathrm{C}$ for $30 \mathrm{~s}, 52^{\circ} \mathrm{C}$ for $30 \mathrm{~s}$, and $72^{\circ} \mathrm{C}$ for $30 \mathrm{~s}$, ending with a final extension at $72^{\circ} \mathrm{C}$ for $5 \mathrm{~min}$.

The RPOC493F-SAC-1039R primer pair produced a 547 bp rpoC1 fragment encompassing a variable region of the $r p o C 1$ gene suitable as a target for probe 
hybridization. The forward primer (RPOC493F) was designed to be more Synechococcus-specific than the SAN-157F that was used to generate rpoC1 clone libraries (Tai \& Palenik 2009), and amplified a smaller fragment more appropriate for the Luminex assay. The length of the PCR amplicon and the location of the target sequence within the PCR amplicon have been shown to affect the success of the hybridization (Diaz \& Fell 2004). The forward primer (RPOC493F) anneals to the rpoC1 gene between primers rpoC1-39F and rpoC1-462R, which previously have been used to document Synechococcus diversity (Muhling et al. 2006).

To test probe specificity, and for use as hybridization standards, PCRs were conducted with genomic DNA from cultured strains, and plasmid DNA from environmental rpoC1 clones. For strain-specific probes, serial dilutions of genomic DNA from Synechococcus CC9311 (Clade I), Synechococcus CC9605 (Clade II), Synechococcus WH8102 Clade III), and Synechococcus CC9902 (Clade IV), ranging in mass from approximately 0.0002 to $2 \mathrm{ng}$, were used in the PCR reactions. For environmental rpoC1 clones, $50 \mathrm{ng}$ of plasmid DNA was used. For environmental samples, typically 1 to $8 \mathrm{ng}$ of DNA was used. The PCRs and subsequent hybridizations were replicated 5 to 6 times.

Mixtures of template DNAs in the PCRs were also tested in the bead-array assay. Genomic DNA from CC9311 and CC9902 were mixed in varying ratios, but maintaining the total DNA amount in the PCRs at $0.125 \mathrm{ng}$.

Hybridization. The hybridization protocols were developed using a 96-well plate to allow for highthroughput sample processing.

To test the hybridization specificity of the beadprobes, a range of hybridization temperatures from 50 to $65^{\circ} \mathrm{C}$ was tested. For the clade probes (probes I-A, II, III, and IV-A), $55^{\circ} \mathrm{C}$ gave the best probe signal with the lowest non-specific hybridization. For the sub-clade probes (probes I-A, I-B, I-C, I-D, I-E, IV-A, IV-B, and IV-C), a hybridization temperature of $58^{\circ} \mathrm{C}$ was chosen. For the mixed-template experiments, probes I-A and IV-A were used at a hybridization temperature of $55^{\circ} \mathrm{C}$.

Initial experiments using DNA from cultured strains for testing the clade probe set were conducted using the following hybridization procedure: $10 \mu \mathrm{l}$ of the biotinylated PCR product was mixed with 5000 beads of each bead-probe in $40 \mu \mathrm{l} 1.5 \times$ TMAC hybridization buffer $\left(4.5 \mathrm{~mol} \mathrm{l}^{-1}\right.$ tetramethyl ammonium chloride, $0.1 \%$ SDS, $4 \mathrm{mmol} \mathrm{l}^{-1}$ EDTA, $50 \mathrm{mmol} \mathrm{l}^{-1}$ Tris, at $\mathrm{pH}$ 8.0) and $10 \mu \mathrm{l}$ water. The biotinylated PCR product was hybridized to the bead-probes by first denaturing the DNA at $95^{\circ} \mathrm{C}$ for 5 min followed by hybridization at $55^{\circ} \mathrm{C}$ for $30 \mathrm{~min}$. The bead-probes were pelleted by centrifugation for $3 \mathrm{~min}$ at $3050 \times g$, the supernatant removed, then the bead-probes were incubated with $4 \mu \mathrm{g} \mathrm{ml}^{-1}$ of strep-PE in 1× TMAC hybridization buffer (a $2 / 3$ dilution of $1.5 \times$ TMAC buffer) for $10 \mathrm{~min}$ at $55^{\circ} \mathrm{C}$. The bead-probes were then analyzed on a Luminex100 instrument following the manufacturer's protocol.

For all other experiments including those involving environmental samples and clones, the protocol was modified to enhance the hybridization signal. The biotinylated PCR products were cleaned and concentrated by ethanol precipitation. Twenty $\mu \mathrm{l}$ of the PCR product was mixed with $2 \mu \mathrm{l}$ of $3 \mathrm{~mol} \mathrm{l}^{-1}$ sodium acetate, pH 5.2, and $40 \mu \mathrm{l}$ of $100 \%$ ethanol. The PCR product was allowed to precipitate at $-20^{\circ} \mathrm{C}$ for $60 \mathrm{~min}$, and was then pelleted by centrifugation at $3050 \times g$ for $60 \mathrm{~min}$ at $4^{\circ} \mathrm{C}$. The supernatant was removed and the DNA pellet was washed with $150 \mu \mathrm{l}$ of $70 \%$ ethanol and centrifuged at $3050 \times g$ for $10 \mathrm{~min}$. The supernatant was again removed and the pellet was left to air-dry. The DNA pellet was resuspended in $15 \mu \mathrm{l}$ or $30 \mu \mathrm{l}$ of $1 \times$ TMAC buffer (except with $0.1 \%$ Sarkosyl instead of SDS), containing 2000 of each clade beadprobe or 3000 of each sub-clade bead-probe to be tested. Denaturation, hybridization, detection, and analysis were the same as described above, except with some modifications for the sub-clade probes. Hybridization was performed at $58^{\circ} \mathrm{C}$ for the sub-clade probes and, after incubating in strep-PE, the strep-PE was replaced with $1 \times$ TMAC buffer and incubated for $5 \mathrm{~min}$ at $58^{\circ} \mathrm{C}$ before analysis.

Analysis. Successful hybridization of the biotinylated PCR amplicons to a particular bead-probe was assessed by the amount of phycoerythrin fluorescence recorded on an arbitrary scale from each bead-probe. One hundred beads of each bead-probe were evaluated for a given sample. The trimmed mean fluorescence relative to background from PCR negative controls (mean fluorescence $\div$ background fluorescence $=$ signal:background ratio) was used to evaluate the hybridizations. The background fluorescence was the average amount of fluorescence from non-specific targets from hybridization controls using cultured isolates or environmental clones. A reliable signal (the detection limit) was considered to be a signal:background ratio $>2$.

For the environmental samples, the signal:background ratio for each probe was normalized for better comparison, since the magnitude of the hybridization signals varied for each probe. The signal:background ratio was divided by the average signal:background ratio from the hybridization controls for each probe.

Statistical analysis. The results from the clade probe set, using samples from the SIO pier time-series, were compared to results obtained from a previous study using qPCR (Tai \& Palenik 2009). The Pearson productmoment correlation coefficients $(\mathrm{r})$ were calculated 
using JMP v. 5.0. Pair-wise correlations were also determined between the sub-clade probe results and total Synechococcus abundances from the SIO pier time-series and the coastal to open-ocean transect.

The significance of changes in the probe signals from the surface to samples at depth from the coastal to open-ocean transect were tested with a paired $t$-test using Prism v. 5.0b.

\section{RESULTS}

\section{Development of the Luminex assay}

Two sets of probes were used in Luminex assays for assessing the diversity and abundance of marine Synechococcus (Table 2). The first set consisted of 4 strainspecific probes (I-A, II, III, and IV-A) designed to hybridize to Synechococcus from Clades I, II, III, and IV (Table 2). The second set consisted of 5 probes (I-A, I-B, I-C, I-D, and I-E) and 3 probes (IV-A, IV-B, and IV-C) targeting sub-clades within Clades I and IV, respectively (Table 2). Probes I-A and IV-A were common to both sets. These probes all target the same region of the rpoC1 gene. Initially, we tested probes that hybridized to different regions of the PCR fragment or that were degenerate, but hybridization signals were not obtained. Similarly, we tested a set of 16S rRNA probes designed to evaluate Synechococcus diversity (Fuller et al. 2003), but these did not produce consistent results with the Luminex assay (data not shown). Different regions of the 16S rRNA gene were targeted by these probes; those that did not produce a Luminex signal targeted the same region of the gene (nucleotide positions 927 to 944). This suggests that for Luminex assays, the location of probe hybridization is crucial, likely due to the secondary structure of the target PCR amplicon.

The sub-clade probes generally matched all the rpoC1 sequences within a phylogenetic cluster, but some exceptions occurred, particularly for the Clade I probes (Fig. 2). In addition, the probes did not capture all the microdiversity. The Clade I-A and IV-A probes, for example, were broad-targeting more than one phylogenetic cluster. Regardless, the sub-clade probes do measure diversity at a taxonomic level below the clade level defined by $16 \mathrm{~S}$ rRNA, providing details about Synechococcus community composition that were previously unknown.

For the clade probes, when using a hybridization temperature of $55^{\circ} \mathrm{C}$, each bead-probe hybridized only to its intended target and not to PCR amplicons from other strains (Fig. 3a). For the sub-clade probe set, a higher hybridization temperature of $58^{\circ} \mathrm{C}$ was required to reduce non-specific hybridization (Fig. 3b). Using this hybridization temperature, and by placing polymorphisms in the middle of the probe sequence, single nucleotide specificity was achieved. Using DNA from cultured strains or from rpoC1 environmental clones, probe hybridization was determined to be specific if the signal:background ratio was $<2$ for non-target probes in the multiplexed assay. All probes were combined into a single set for hybridization at $58^{\circ} \mathrm{C}$, but these data are not presented because the results for the Clade II and III probes were consistently below the detection limit (signal:background ratio <2). Using a higher hybridization temperature and multiplexing with additional probes likely reduced the hybridization signals for the Clade II and III probes. In any case, these were difficult to detect because of their low abundance (Tai \& Palenik 2009, V. Tai \& B. Palenik unpubl. data).
Fig. 3. Luminex hybridization specificity using (a) the clade probe set hybridized to Synechococcus strain CC9311, a cultured representative of Clade I, and (b) the sub-clade probe set hybridized to an environmental rpoC1 Clade I clone. In both cases, the Luminex signal is specific for probe I-A. All other probes have near background levels of signal (signal:background ratio $=1$ ). Luminex signal: background ratio levels obtained for (c) the clade probes, and (d) the subclade probes using DNA standards from cultured Synechococcus strains or environmental rpoC1 clones. For each experiment, $2.5 \mathrm{ng}$ of template DNA from cultured strains and $50 \mathrm{ng}$ from environmental clones were used. The mean $( \pm \mathrm{SE})$ signal:background ratio from 6 replicates is shown
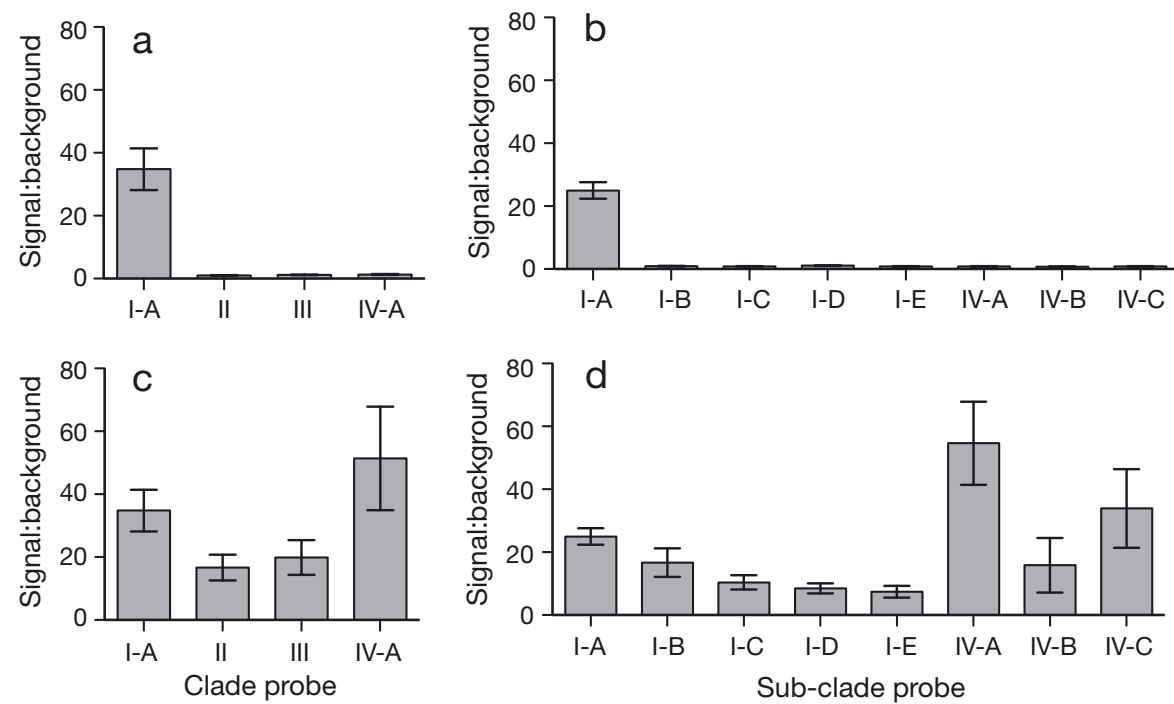
Using the protocol developed here, the hybridization signal increased log-linearly over 4 orders of magnitude, ranging from 0.0002 to $2 \mathrm{ng}$ of starting template DNA (data not shown). The overall signal increased if the PCR amplicons were ethanol-precipitated before hybridization (data not shown). Ethanol precipitation removed excess primers that may have been interfering with the hybridization. It also concentrated the biotinylated PCR product, resulting in a higher hybridization signal per bead. Although the hybridization signal increased with increasing amounts of template in the PCR reactions, large statistical errors in determining the mean signal:background ratio from replicate assays prevented precise abundances to be calculated. However, relative abundances and the observed trends in the Luminex signals are accurate.

Each bead-probe did not result in the same magnitude of hybridization signal, given the same amount of starting template. Probe IV-A gave the best signal, while the I-E probe gave the weakest signal (Fig. 3c,d). As PCR efficiency was similar for control reactions, the differences in hybridization signal were likely due to the capacity of a given probe to hybridize efficiently to its target, which could be affected by secondary structure of the target or probe, or the density of the probes coupled onto the beads (Diaz \& Fell 2004). The average recorded PE signal (on an arbitrary scale) for probe IV-A ranged from 50 (for at least a 2-fold signal above background) to 1250 , with a signal:background ratio of 50 .

Using a mixture of CC9311 and CC9902 DNA templates in the PCR, the bead-array assay successfully discriminated the templates and their expected proportions (Fig. 4). Because hybridization to the probes is highly specific, similar results would be achieved with more complex mixtures.

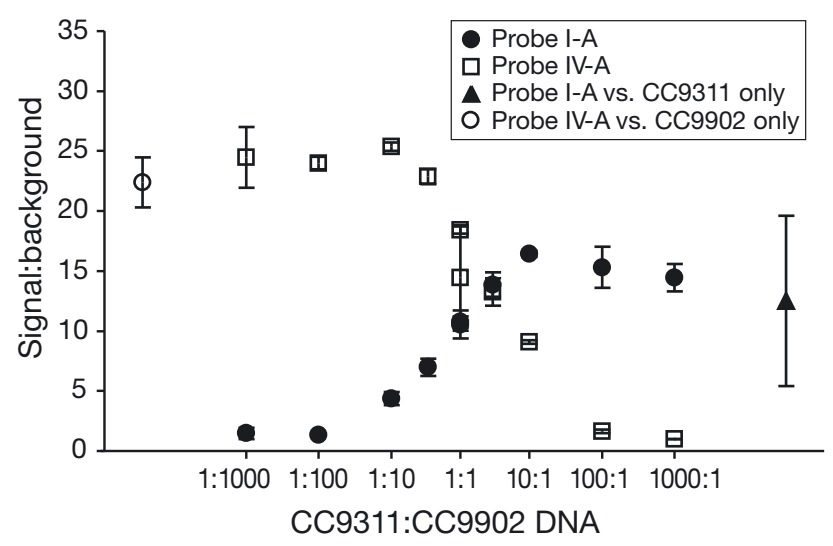

Fig. 4. Luminex signals from probes I-A and IV-A using a mixture of template DNA from Synechococcus strains CC9311 and CC9902. A total of $0.125 \mathrm{ng}$ DNA was used in the PCR for each assay while varying the ratio of CC9311:CC9902 DNA

\section{Environmental samples}

Synechococcus rpoC1 fragments were amplified and biotinylated by PCR using the RPOC493F and SAC1039R primer pair from DNA extracted from environmental samples. The clade probe set was used to assay the composition of the Synechococcus population and their dynamics from samples collected over 1 yr from the SIO pier in 2006. These samples and the samples collected along a coastal to open-ocean transect in the summer of 2007 were evaluated with the sub-clade probe set.

\section{SIO pier time-series}

From samples collected approximately once per month over $1 \mathrm{yr}$, hybridization signals were consistently high at the SIO pier for probes I-A and IV-A, indicating that Synechococcus from Clades I and IV are the 2 most abundant throughout the year (Fig. 5a). Signals to probes II and III were absent or very low. These hybridization results are consistent with previously reported data using qPCR (Tai \& Palenik 2009). The Luminex hybridization signals were significantly correlated with the qPCR results for Clades II, III, and IV (Table 3). The probe IV-A Luminex hybridization signal also correlated significantly with total Synechococcus abundances determined by flow cytometry (Table 3).

It was expected that the dynamics of the I-A probe would also correlate with Clade I abundances determined using $\mathrm{qPCR}$, but they did not (Table 3). This result is surprising, as the relatively high Luminex signals from the I-A probe suggested that Synechococcus from this sub-clade were dominant in this environment. The lack of correlation may reside in the diversity of Synechococcus from Clade I. However, based on rpoC1 environmental libraries, while the I-A probe hybridizes to most of the Clade I Synechococcus during certain times of the year, other variants may form a significant component of the total Clade I abundance.

The sub-clade probe set was used to test this hypothesis and to examine the dynamics of Synechococcus microdiversity from the SIO pier time-series (Fig. 5b,c,d). Even though a higher hybridization temperature was used for this probe set, the results for probes I-A and IV-A were very similar to those obtained at the lower hybridization temperature (correlation coefficients of 0.780 and 0.931 , respectively). Several of the sub-clade probes showed similar dynamics. Luminex signals from probes I-A and I-B, I$\mathrm{C}$ and I-D, I-C and IV-B, IV-A and IV-C, and IV-A and total Synechococcus were highly correlated (Table 4). In addition, the Luminex results for I-C and IV-B also 

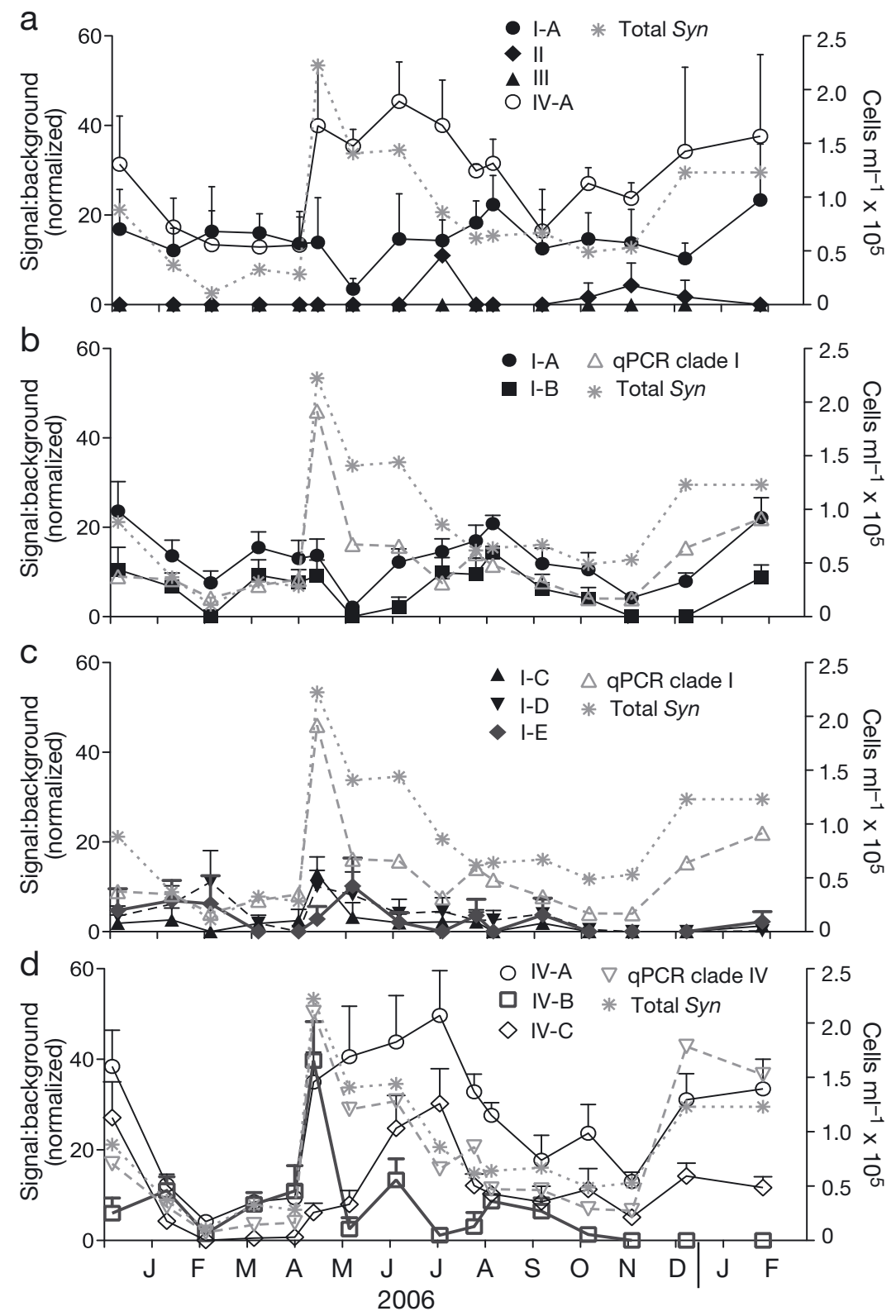

Fig. 5. Temporal dynamics of Synechococcus clades and sub-clades over 1 yr from the SIO pier using the Luminex bead-array. (a) Clade probes I-A, II, III, and IV-A; (b) sub-clade probes I-A and I-B; (c) sub-clade probes I-C, I-D, and I-E; (d) sub-clade probes IV-A, IV-B, and IV-C. qPCR and total Synechococcus abundances are from Tai \& Palenik (2009). The normalized mean (+SE) signal:background ratio from 5 or 6 replicates is shown. For clarity, the error bar is shown only above the mean. Where no error bar is visible, it is smaller than the height of the symbol

significantly correlated with Clade I abundances determined using qPCR (Tai \& Palenik 2009). Therefore, over $1 \mathrm{yr}$, sub-clade I-C may have been the dominant Clade I type at the SIO pier. Unfortunately, the signal for this probe was generally low, so further confirmation, perhaps with clone libraries, is needed. Alternatively, Clade I types that are usually rare may occasionally bloom and become dominant, meaning that these rare types might have been missed by the rpoC1 environmental libraries and the sub-clade probes. It was not expected, however, that a Clade IV probe would also correlate with Clade I abundances. These results suggest that Synechococcus targeted by probes I-C and IV-B may have somewhat similar ecological niches.

\section{Coastal to open-ocean transect}

The sub-clade probe set was also used to assess the spatial distribution of Synechococcus along a transect from the coast (a point $10 \mathrm{~km}$ away from the SIO pier) to oligotrophic waters $687 \mathrm{~km}$ off shore. From the coast to open ocean, total Synechococcus and the Luminex signals for all sub-clade probes consistently decreased, both from surface samples and from samples taken at depth, although a distinct peak was observed at Stn 93.45 (Fig. 6), associated with a possible upwelling event (C. Dupont, R. Bundy \& K. Barbeau unpubl. data). A sharp decrease in total Synechococcus abundances occurred at Stn 93.80, coinciding with a drop in the nitricline, thermocline, and fluorescence maximum depths (Table 1; C. Dupont, R. Bundy \& K. Barbeau unpubl. data). Sub-clade abundances at depth also became very low at Stn 93.80, while at the surface, low sub-clade abundances began at Stn 93.65.

The Luminex signals from each subclade probe were significantly correlated to all other sub-clade probes and total Synechococcus abundances (data not shown). In other words, all sub-clade probes shared a common coast-to-openocean trend, as described above. The correlations reflect that, in general, all Clade I and IV Synechococcus are similarly affected by the dominant environmental changes from the coast to open ocean. The pattern of decreasing total Synechococcus abundances from the coast to off-shore is consistent with previous descriptions of the Southern California Bight (Collier \& Palenik 2003).

Examining each station individually revealed subtler differences in the distribution of the sub-clades. For each station, the change in sub-clade composition from the surface to the Synechococcus and fluorescence 
Table 3. Pairwise correlation coefficients of Luminex hybridization signals between clade probes, total Synechococcus abundance, and Clade I, II, III and IV abundances determined using qPCR from a 1 yr time-series of surface samples from the SIO pier. Correlation coefficients in bold have a p-value $<0.05\left({ }^{*} \mathrm{p}<0.005\right)$. qPCR abundances are from Tai \& Palenik (2009)

\begin{tabular}{|c|c|c|c|c|c|c|c|c|}
\hline & $\begin{array}{l}\text { Probe } \\
\text { I-A }\end{array}$ & $\begin{array}{l}\text { Probe } \\
\text { II }\end{array}$ & $\begin{array}{c}\text { Probe } \\
\text { III }\end{array}$ & $\begin{array}{l}\text { Probe } \\
\text { IV-A }\end{array}$ & $\begin{array}{l}\text { Total } \\
\text { Syn }\end{array}$ & $\begin{array}{c}\text { qPCR } \\
\text { Clade I }\end{array}$ & $\begin{array}{c}\text { qPCR } \\
\text { Clade II }\end{array}$ & $\begin{array}{c}\text { qPCR } \\
\text { Clade III }\end{array}$ \\
\hline Probe II & -0.050 & & & & & & & \\
\hline Probe III & 0.036 & 0.545 & & & & & & \\
\hline Probe IV-A & 0.030 & 0.264 & -0.045 & & & & & \\
\hline Total Syn & -0.202 & -0.095 & -0.314 & $0.809^{*}$ & & & & \\
\hline qPCR clade I & 0.005 & -0.315 & -0.438 & 0.562 & $0.874^{*}$ & & & \\
\hline qPCR clade II & -0.210 & 0.699* & 0.526 & 0.264 & 0.083 & -0.143 & & \\
\hline qPCR clade III & -0.093 & 0.359 & $0.669^{*}$ & 0.281 & 0.054 & -0.231 & 0.358 & \\
\hline qPCR clade IV & -0.120 & -0.112 & -0.262 & $0.776^{*}$ & $0.935^{*}$ & $0.848^{*}$ & 0.241 & -0.003 \\
\hline
\end{tabular}

Table 4. Pairwise correlation coefficients of Luminex hybridization signals between sub-clade probes, total Synechococcus abundance, and Clade I and IV abundances determined using qPCR from a 1 yr time-series of surface samples from the SIO pier. Correlation coefficients in bold have a p-value $<0.05\left({ }^{*} \mathrm{p}<0.005\right)$. qPCR abundances are from Tai \& Palenik (2009)

\begin{tabular}{|c|c|c|c|c|c|c|c|c|c|c|}
\hline & $\begin{array}{c}\text { Probe } \\
\text { I-A }\end{array}$ & $\begin{array}{c}\text { Probe } \\
\text { I-B }\end{array}$ & $\begin{array}{c}\text { Probe } \\
\text { I-C }\end{array}$ & $\begin{array}{c}\text { Probe } \\
\text { I-D }\end{array}$ & $\begin{array}{c}\text { Probe } \\
\text { I-E }\end{array}$ & $\begin{array}{c}\text { Probe } \\
\text { IV-A }\end{array}$ & $\begin{array}{c}\text { Probe } \\
\text { IV-B }\end{array}$ & $\begin{array}{l}\text { Probe } \\
\text { IV-C }\end{array}$ & $\begin{array}{l}\text { Total } \\
\text { Syn }\end{array}$ & $\begin{array}{l}\text { qPCR } \\
\text { clade I }\end{array}$ \\
\hline Probe I-B & $0.876^{*}$ & & & & & & & & & \\
\hline Probe I-C & 0.246 & 0.519 & & & & & & & & \\
\hline Probe I-D & -0.128 & 0.159 & $0.692^{*}$ & & & & & & & \\
\hline Probe I-E & 0.199 & 0.357 & 0.512 & 0.636 & & & & & & \\
\hline Probe IV-A & 0.215 & 0.160 & 0.243 & 0.087 & 0.231 & & & & & \\
\hline Probe IV-B & 0.171 & 0.373 & $0.893^{*}$ & 0.530 & 0.223 & 0.091 & & & & \\
\hline Probe IV-C & 0.339 & 0.214 & -0.028 & -0.055 & -0.017 & $0.825^{*}$ & -0.127 & & & \\
\hline Total Syn & 0.005 & -0.038 & 0.517 & 0.194 & 0.176 & $0.710^{*}$ & 0.521 & 0.340 & & \\
\hline qPCR clade I & 0.153 & 0.176 & $0.715^{*}$ & 0.291 & 0.240 & 0.425 & $0.744^{*}$ & 0.005 & $0.874^{*}$ & \\
\hline qPCR clade IV & 0.042 & -0.084 & 0.336 & 0.045 & 0.113 & 0.661 & 0.363 & 0.299 & $0.935^{*}$ & $0.848^{*}$ \\
\hline
\end{tabular}

maximum was plotted (Fig. S1 in the Supplement, available at www.int-res.com/articles/suppl/m426p133_ supp.pdf). The results were grouped based on the Luminex hybridization results of the sub-clade probes that showed similar trends. With the exception of Stns 93.80 and 93.90, Luminex signals to sub-clade probes I-A, I-B, and IV-B showed similar trends with depth. This is in contrast to the SIO pier time-series, in which the results for sub-clade probe IV-B correlated with sub-clade probe I-C.

For Stns 93.26, 93.35, and 93.40, hybridization to sub-clade probes I-A, I-B, and IV-B increased from the surface to the Synechococcus and fluorescence maxima in parallel to the trend observed with total Synechococcus abundances. In contrast, hybridization to sub-clades IV-A and IV-C decreased with depth.

At Stn 93.45, the Luminex signals to sub-clades IV-A and IV-C again decreased with depth. For sub-clades I-A, I-B, and IV-B, the signals decreased from the surface to the Synechococcus maximum, then slightly increased at the fluorescence maximum, but these changes were not statistically significant. At this station, a reliable signal (signal:background ratio $>2$ ), decreasing with depth, could be detected at the surface for sub-clades I-C and I-D. A reliable signal for sub-clade I-E could not be detected.

At Stns 93.50 and 93.65, all the sub-clade probes and total Synechococcus showed similar trends. For Stn 93.50, the Luminex signals increased slightly from the surface to the Synechococcus maximum, then decreased slightly or remained the same at the fluorescence maximum. For Stn 93.65, the Luminex signals increased from the surface to the Synechococcus/fluorescence maximum.

Stns 93.80 and 93.90 showed a very different pattern. The signal for probe IV-B consistently increased from the surface to the fluorescence maximum, whereas reliable signals were not detected for any of the other sub-clade probes. The magnitude of the sub-clade IVB signal, however, was lower than from the more coastal stations. Total Synechococcus abundances did not exactly match the sub-clade IV-B trend even though this was the only Synechococcus sub-clade detected at these stations. For Stn 93.80, Synechococcus abundances increased with depth but were low at the fluorescence maximum. 


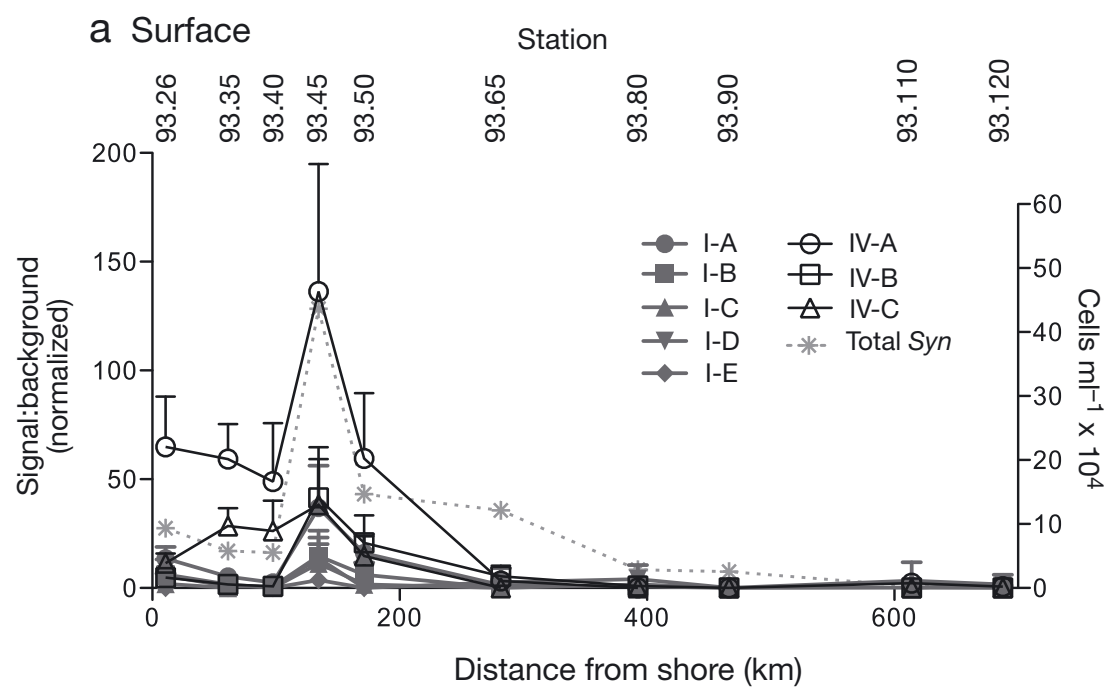

b Synechococcus maximum

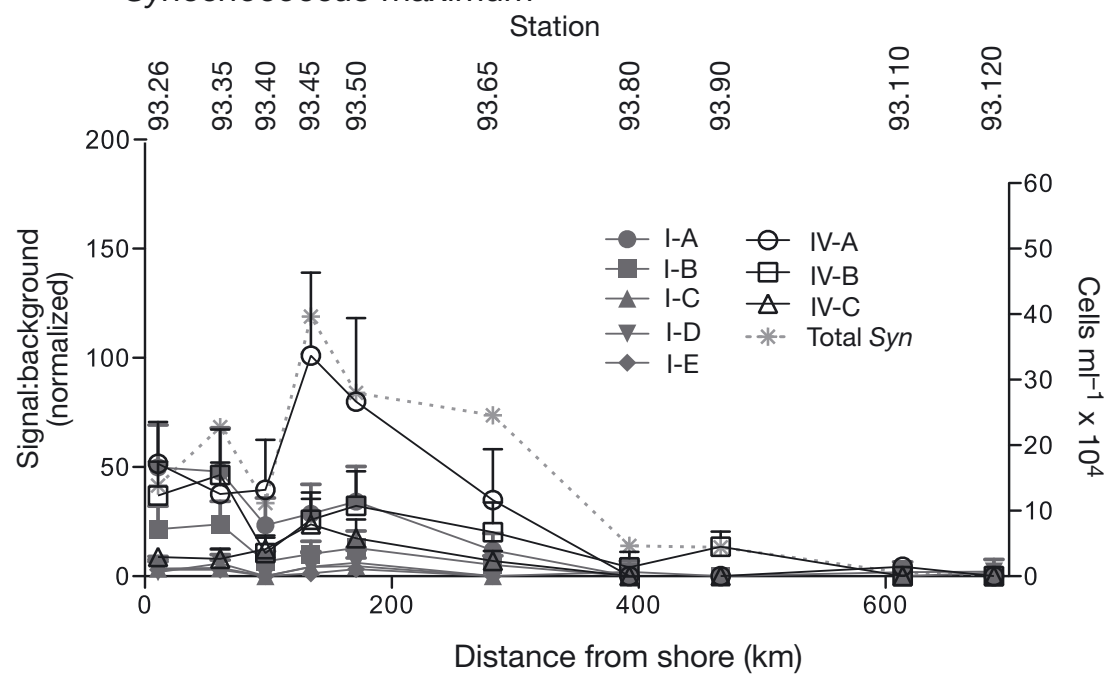

Fig. 6. Sub-clade Luminex signals (normalized) and total Synechococcus abundances from (a) the surface, and (b) depths of the Synechococcus maxima along the Line 93 transect

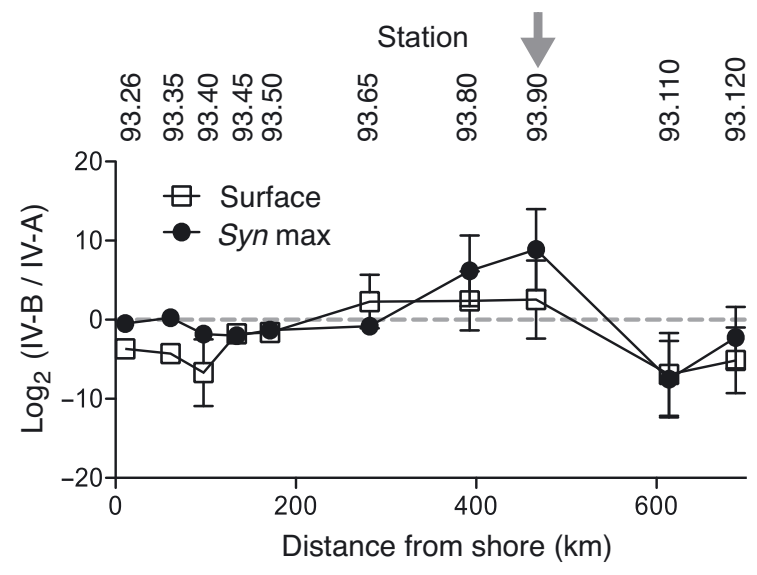

Over the transect, the distribution of Synechococcus targeted by probe IVB was clearly distinct in mesotrophic waters. Relative to IV-A, which was a dominant sub-clade at the coastal stations, IV-B became increasingly dominant away from the coast and was the dominant sub-clade at depth at Stns 93.80 and 93.90 (Fig. 7).

Hybridization to the sub-clade probes was not detected from the 2 oligotrophic stations $(93.110$ and 93.120), except for probe IV-A (Figs. 5 \& S1). At Stn 93.110, the signal for probe IV-A increased slightly from the surface to the Synechococcus maximum, then decreased at $100 \mathrm{~m}$, following the trend in total Synechococcus. The abundance of Synechococcus was very low at these stations, so it is not surprising that little was detected with the sub-clade probes.

At Stns 93.45, 93.80, 93.110, and 93.120, because changes in the hybridization signals to the probes for Clades I and IV did not match the distribution of total Synechococcus abundances with depth, the probes did not account for all the total Synechococcus abundances enumerated by flow cytometry. Synechococcus other than those belonging to Clades I and IV do occur in the Southern California Bight (Toledo \& Palenik 1997, Ferris \& Palenik 1998) and may have been abundant at these stations. Synechococcus from Clades II and III have been detected along the transect using qPCR (Tai \& Palenik unpubl. data), but at low abundances. Also, an unnamed clade represented by Synechococcus strains CC9305-3, CC9317, and CC9318, isolated from an open-ocean station in the Southern California Bight (Toledo \& Palenik 1997, Muhling et al. 2006), was not probed. Finally, subclade probes could not be designed to target all the Synechococcus within Clades I and IV. In particular,

Fig. 7. Relative signal:background ratio (normalized) of probes IV-B to IV-A, shown on a $\log _{2}$ scale, along the Line 93 transect. Values above the dotted line indicate that IV-B was dominant relative to IV-A, and values below the line indicate that IV-A was dominant relative to IV-B. The arrow points to the mesotrophic station 93.90 where the signal for probe IV-B was dominant at depth 
Synechococcus that are usually rare but might occasionally bloom to high abundances could have been missed. However, as the probes were designed from the most abundant sequences from environmental libraries collected from various locations and seasons in the Southern California Bight, the dominant subclades were targeted.

\section{DISCUSSION}

A Luminex bead-array assay was developed for high-throughput multiplex detection of marine Synechococcus from environmental samples. Using mixtures of 4 and 8 probes, the temporal and spatial distributions of clades and sub-clades of Synechococcus were determined. The assay can be easily augmented to include more probes, either from other taxa within the marine Synechococcus or from different taxa altogether, as the Luminex bead-array can accommodate up to 100 different beads. Probes have been recently developed for phytoplankton and heterotrophic bacteria from the coastal Southern California Bight (Mayali et al. 2010), and these could be combined with the Synechococcus probes to create a rapid assay for marine microbial ecology. However, the success of the Luminex assay depends on a combination of many factors, including the size of the PCR product or target DNA, secondary structure of the target DNA, relative location of the probe sequence on the target DNA, and the subsequent hybridization and detection conditions. These factors become even more critical when dealing with environmental DNA samples that may contain PCR inhibitors or low amounts of target DNA. Thus careful evaluation of the assay is vital.

\section{Evaluation of the Luminex assay for Synechococcus}

The 4 Synechococcus clades evaluated for the Luminex assay were chosen because they were known to be the most abundant types in this Pacific coastal environment. Over a $1 \mathrm{yr}$ time-series from the SIO pier, the Luminex assay corroborated previous results using qPCR to quantify Synechococcus clades, especially for Clades II, III and IV (Tai \& Palenik 2009). Changes in relative abundance were readily observed and strong correlations of the mean signal:background ratio with qPCR data showed that both methods concur, and that the Luminex assay accurately represents the relative temporal trends. The advantage of Luminex hybridizations over qPCR shown in our evaluation is that only a single assay was required to obtain data for all 4 clades.
Quantification, however, was less precise using Luminex hybridizations. For Luminex hybridizations, the signal was log-linear over approximately 4 orders of magnitude of target template DNA, whereas it spanned 6 orders of magnitude in qPCR. Especially for targets of low abundance, the Luminex assay was not as sensitive as qPCR. For example, Synechococcus from Clade III were of very low abundance at the SIO pier. Using the Luminex bead-probes, a reliable signal (signal:background ratio $>2$ ) was never obtained for the Clade III probe, whereas low Clade III abundances were detected in the winter and late summer using qPCR (Tai \& Palenik 2009).

The Luminex assay has the advantage over qPCR for evaluating Synechococcus microdiversity. The rpoC1 gene provided sufficient variability to examine diversity within clades also defined by $16 \mathrm{~S}$ rRNA and internal transcribed spacer (ITS) sequences (Rocap et al. 2002, Fuller et al. 2003). Using this variation, many probes can be evaluated simultaneously with the Luminex assay. Eight probes were used here to examine microdiversity within the dominant Clades I and IV of the Southern California Bight. In contrast, qPCR can have a maximum of 4 targets in a multiplex reaction, determined by the number of fluorescent colors distinguishable by real-time PCR instruments.

\section{Biogeography of Synechococcus microdiversity}

Synechococcus from Clades I and IV are often found together in coastal environments, including the coastal Southern California Bight (Brown et al. 2005, Zwirglmaier et al. 2008, Tai \& Palenik 2009). The factors that regulate their co-existence and relative dynamics, however, are not well understood. The Luminex bead-array was used to examine the distribution of sub-clades within Clades I and IV using representative sub-clade probes, and these results further demonstrate the complexity of clade and subclade biogeography.

Many of the sub-clade probes have varying temporal and spatial dynamics, suggesting that Synechococcus sub-clades occupy different ecological niches. Others have highly correlated dynamics - specifically, subclade probes I-A and I-B; and IV-A and IV-C. Sub-clade probes I-A and I-B generally targeted Synechococcus belonging to the same larger phylogenetic cluster, as did sub-clade probes IV-A and IV-C (Fig. 2). That these related pairs of sub-clade probes shared similar biogeographic patterns suggest that there is a strong genetic component regulating their distributions and that their ecological niches may overlap. However, the extent of the overlap and the factors maintaining their genetic distinctiveness are not known. 


\section{Coastal to open-ocean transect}

The composition of the Synechococcus communities from the coast-to-open-ocean transect generally changed with the nitricline, thermocline, and fluorescence maximum depths. As the stations progressed off-shore, the nitricline, thermocline, and fluorescence maxima deepened, showing distinct drops at Stns 93.80 (mesotrophic) and 93.110 (oligotrophic) (Table 1; C. Dupont, R. Bundy \& K. Barbeau unpubl. data). These transitions were matched by changes in the Synechococcus community composition. Thus, the dominant environmental transitions observed from the coast to off-shore have a significant role in regulating the distribution of Synechococcus sub-clades in the Southern California Bight.

The coastal stations were dominated by Luminex signals to sub-clade probes IV-A and IV-C at the surface, which decreased with depth, and subclade probes I-A, I-B, and IV-B which increased at depth. In mesotrophic waters (Stns 93.80 and 93.90), only signals to sub-clade probe IV-B were detected and increased with depth, suggesting that Synechococcus targeted by this probe were dominant. In oligotrophic waters (Stns. 93.110 and 93.120), low signals to sub-clade probe IV-A were detected. In oligotrophic environments, however, Synechococcus clades other than I and IV, such as Clade II, may be dominant (Ferris \& Palenik 1998, Toledo \& Palenik 2003).

The Luminex signals for probes I-C, I-D, and I-E were generally very low along this transect, but the general trends were similar to probes I-A and I-B. Therefore, the depth preference observed for probes I-A and I-B at the coastal stations might apply for all Synechococcus from Clade I. Subtle changes in the distribution of Synechococcus targeted by probes I-C, I-D, and I-E, however, would not have been detected using the Luminex assay.

Using flow cytometry, marine Synechococcus also showed distinct fluorescence and scattering changes from coastal to open-ocean environments and with depth in the Southern California Bight (Collier \& Palenik 2003). These changes may be due to physiological conditions, such as light or nutrient levels, but genetic differences are also possible, or indeed probable, especially given the changes in Synechococcus biogeography observed with the Luminex assay.

The Luminex signals for sub-clade probe IV-B had a very distinct spatial distribution, being dominant at depth in mesotrophic waters. In these environments, the nitricline and thermocline depths deepened to below $50 \mathrm{~m}$, compared to $\leq 35 \mathrm{~m}$ near the coast. At depth, Synechococcus targeted by probe IV-B may be capable of photosynthesizing under lower light condi- tions while gaining access to higher nutrient concentrations.

The sequences that match the sub-clade IV-B probe grouped together in a taxonomic cluster separate from CC9902, BL107 and other Clade IV Synechococcus (Fig. 2). Most of the sub-clade IV-B sequences were obtained from a near-shore station at the chlorophyll maximum. Two distinct Clade IV clusters were also observed using environmental sequences of the nitrate reductase gene (narB) from Monterey Bay, California (Jenkins et al. 2006). It is likely that these Clade IV clusters are from the same Synechococcus types observed with the rpoC1 sequence phylogeny. However, since the rpoC1 and narB Clade IV phylogenies comprise mainly environmental sequences, the linkage between the rpoC1 and narB clusters remains to be proven.

\section{Genetic factors regulating Synechococcus biogeography}

The Luminex assay provided a rapid and accurate tool for tracking multiple groups of microbes simultaneously. At a taxonomic level below that which can be resolved using 16S rRNA sequences, distinct distributions for marine Synechoccoccus taxa were found. But as these distributions were based on polymorphisms within a single gene marker, the genes and the genetic polymorphisms that play a role in regulating their distribution are not yet known.

At least 10 different genome sequences are available for marine Synechococcus strains (Palenik et al. 2003, 2006, Dufresne et al. 2008). These sequencing efforts have focused on diversity across the breadth of marine Synechococcus. However, as we have shown here, biogeographic distributions of Synechococcus also vary within clades.

Within Clade IV, genome sequences from 2 strains, CC9902 and BL107, have been sequenced and compared (Dufresne et al. 2008). While the majority of the genes are shared and are largely syntenic between the 2 genomes, each genome also contains genes that the other does not. These unique genes often have functions in transport or cell-wall modification, implying a role in nutrient acquisition or grazer and phage avoidance. However, the distribution and ecological niches of these 2 strains have not been directly examined, and the ecological roles of the genetic differences have not been determined. Ideally, the genome sequence from a Synechococcus isolate targeted by sub-clade probe IV-B could be examined, as we have shown that these Synechococcus have a biogeographical distribution distinct from that of strains CC9902 and BL107. Thus they must also have a distinct set of genes or other 
genetic changes to take advantage of mesotrophic environments at depth. In contrast, Synechococcus targeted by probes IV-A and IV-C likely share genetic strategies to occupy similar ecological niches.

\section{CONCLUSIONS}

To understand the genetic and environmental factors driving the ecology and population dynamics of Synechococcus, sampling efforts should be centered upon relevant temporal and spatial scales. Using the Luminex assay, a picture of Synechococcus biogeography emerged, indicating that sub-clades of Synechococcus have unique ecological niches with distinct distributions within the scale of the Southern California Bight. With continued and coordinated sampling of the Southern California Bight, including genomic, metagenomic (Palenik et al. 2009), physical, and chemical approaches, this environment may prove to be a model ecosystem for understanding marine microbial adaptations and responses to environmental change.

Acknowledgements. Many thanks to C. Dupont for collecting samples and to R. Bundy and K. Barbeau for providing access to unpublished data from the Deep Chlorophyll Maximum 2007 (DCM07) cruise. D. Lucas and C. Dupont were also invaluable in providing sampling opportunities off Mission Beach, San Diego, California in August 2006. Thanks as well to R. Chastain, K. Jessoe, and R. Urbano for assistance with rpoC1 library sequencing. Most of this project was funded by a National Science Foundation grant (NSF OCE05-26979) to B.P. and R.S.B. The research was conducted in association with the California Current Ecosystem-Long Term Ecological Research (CCE-LTER) program.

\section{LITERATURE CITED}

Ahlgren NA, Rocap G (2006) Culture isolation and cultureindependent clone libraries reveal new marine Synechococcus ecotypes with distinctive light and N physiologies. Appl Environ Microbiol 72:7193-7204

Bandyopadhyay K, Kellar KL, Moura I, Cristina M and others (2007) Rapid microsphere assay for identification of Cryptosporidium hominis and Cryptosporidium parvum in stool and environmental samples. J Clin Microbiol 45: 2835-2840

Baums IB, Goodwin KD, Kiesling T, Wanless D, Diaz MR, Fell JW (2007) Luminex detection of fecal indicators in river samples, marine recreational water, and beach sand. Mar Pollut Bull 54:521-536

Brown MV, Fuhrman JA (2005) Marine bacterial microdiversity as revealed by internal transcribed spacer analysis. Aquat Microb Ecol 41:15-23

Brown MV, Schwalbach MS, Hewson I, Fuhrman JA (2005) Coupling 16S-ITS rDNA clone libraries and automated ribosomal intergenic spacer analysis to show marine microbial diversity: development and application to a time series. Environ Microbiol 7:1466-1479

Campbell L, Carpenter EJ (1987) Characterization of phycoerythrin-containing Synechococcus spp. populations by immunofluorescence. J Plankton Res 9:1167-1181

Collier JL, Palenik B (2003) Phycoerythrin-containing picoplankton in the Southern California Bight. Deep-Sea Res II 50:2405-2422

> Collier JL, Brahamsha B, Palenik B (1999) The marine cyanobacterium Synechococcus sp. WH7805 requires urease (urea amidohydrolase, EC 3.5.1.5) to utilize urea as a nitrogen source: molecular-genetic and biochemical analysis of the enzyme. Microbiology 145:447-459

Diaz MR, Fell JW (2004) High-throughput detection of pathogenic yeasts of the genus Trichosporon. J Clin Microbiol 42:3696-3706

Dufresne A, Ostrowski M, Scanlan DJ, Garczarek L and others (2008) Unraveling the genomic mosaic of a ubiquitous genus of marine cyanobacteria. Genome Biol 9:R90

$>$ Ellison CK, Burton RS (2005) Application of bead array technology to community dynamics of marine phytoplankton. Mar Ecol Prog Ser 288:75-85

Ferris MJ, Palenik B (1998) Niche adaptation in ocean cyanobacteria. Nature 396:226-228

Fuhrman JA, Griffith JF, Schwalbach MS (2002) Prokaryotic and viral diversity patterns in marine plankton. Ecol Res 17:183-194

Fuhrman JA, Hewson I, Schwalbach MS, Steele JA, Brown MV, Naeem S (2006) Annually reoccurring bacterial communities are predictable from ocean conditions. Proc Natl Acad Sci USA 103:13104-13109

Fuller NJ, Marie D, Partensky F, Vaulot D, Post AF, Scanlan DJ (2003) Clade-specific 16S ribosomal DNA oligonucleotides reveal the predominance of a single marine Synechococcus clade throughout a stratified water column in the Red Sea. Appl Environ Microbiol 69:2430-2443

Fuller NJ, Tarran GA, Yallop M, Orcutt KM, Scanlan DJ (2006) Molecular analysis of picocyanobacterial community structure along an Arabian Sea transect reveals distinct spatial separation of lineages. Limnol Oceanogr 51:2515-2526

> Huber JA, Mark Welch D, Morrison HG, Huse SM, Neal PR, Butterfield DA, Sogin ML (2007) Microbial population structures in the deep marine biosphere. Science 318:97-100

> Jenkins BD, Zehr JP, Gibson A, Campbell L (2006) Cyanobacterial assimilatory nitrate reductase gene diversity in coastal and oligotrophic marine environments. Environ Microbiol 8:2083-2095

Johnson PW, Sieburth JM (1979) Chroococcoid cyanobacteria in the sea: a ubiquitous and diverse phototropic biomass. Limnol Oceanogr 24:928-935

Lucas AJ, Dupont CL, Tai V, Largier JL, Palenik B, Franks PJS (2011) The green ribbon: multiscale physical control of phytoplankton productivity and community structure over a narrow continental shelf. Limnol Oceanogr 56(2): 611-626

> Mayali X, Palenik B, Burton RS (2010) Dynamics of marine bacterial and phytoplankton populations using multiplex liquid bead array technology. Environ Microbiol 12: 975-989

> Moore LR, Goericke R, Chisholm SW (1995) Comparative physiology of Synechococcus and Prochlorococcus: influence of light and temperature on growth, pigments, fluorescence and absorptive properties. Mar Ecol Prog Ser 116:259-275

> Moore LR, Ostrowski M, Scanlan DJ, Feren K, Sweetsir T (2005) Ecotypic variation in phosphorus-acquisition mechanisms within marine picocyanobacteria. Aquat Microb Ecol 39:257-269

Mühling M, Fuller NJ, Somerfield PJ, Post AF and others (2006) High resolution genetic diversity studies of marine 
Synechococcus isolates using rpoc1-based restriction fragment length polymorphism. Aquat Microb Ecol 45: 263-275

> Nocker A, Burr M, Camper AK (2007) Genotypic microbial community profiling: a critical technical review. Microb Ecol 54:276-289

Palenik B (2001) Chromatic adaptation in marine Synechococcus strains. Appl Environ Microbiol 67:991-994

Palenik B, Brahamsha B, Larimer FW, Land M and others (2003) The genome of a motile marine Synechococcus. Nature 424:1037-1042

Palenik B, Ren QH, Dupont CL, Myers GS and others (2006) Genome sequence of Synechococcus CC9311: insights into adaptation to a coastal environment. Proc Natl Acad Sci USA 103:13555-13559

> Palenik B, Ren Q, Tai V, Paulsen IT (2009) Coastal Synechococcus metagenome reveals major roles for horizontal gene transfer and plasmids in population diversity. Environ Microbiol 11:349-359

Rocap G, Distel DL, Waterbury JB, Chisholm SW (2002) Resolution of Prochlorococcus and Synechococcus ecotypes by using 16S-23S ribosomal DNA internal transcribed spacer sequences. Appl Environ Microbiol 68:1180-1191

Scorzetti G, Brand LE, Hitchcock GL, Rein KS, Sinigalliano CD, Fell JW (2009) Multiple simultaneous detection of Harmful Algal Blooms (HABs) through a high throughput bead array technology, with potential use in phytoplankton community analysis. Harmful Algae 8:196-211

Su Z, Mao FL, Dam P, Wu HW and others (2006) Computational inference and experimental validation of the nitrogen assimilation regulatory network in cyanobacterium

Editorial responsibility: Graham Savidge, Portaferry, UK
Synechococcus sp. WH 8102. Nucleic Acids Res 34: 1050-1065

Tai V, Palenik B (2009) Temporal variation of Synechococcus clades at a coastal Pacific Ocean monitoring site. ISME J 3:903-915

Toledo G, Palenik B (1997) Synechococcus diversity in the California current as seen by RNA polymerase (rpoC1) gene sequences of isolated strains. Appl Environ Microbiol 63:4298-4303

Toledo G, Palenik B (2003) A Synechococcus serotype is found preferentially in surface marine waters. Limnol Oceanogr 48:1744-1755

Toledo G, Palenik B, Brahamsha B (1999) Swimming marine Synechococcus strains with widely different photosynthetic pigment ratios form a monophyletic group. Appl Environ Microbiol 65:5247-5251

Waterbury JB, Watson SW, Guillard RRL, Brand LE (1979) Widespread occurrence of a unicellular, marine, planktonic, cyanobacterium. Nature 277:293-294

> Yang L, Tran DK, Wang X (2001) BADGE, BeadsArray for the Detection of Gene Expression, a high-throughput diagnostic bioassay. Genome Res 11:1888-1898

> Zwirglmaier K, Heywood JL, Chamberlain K, Woodward EMS, Zubkov MV, Scanlan DJ (2007) Basin-scale distribution patterns of picocyanobacterial lineages in the Atlantic Ocean. Environ Microbiol 9:1278-1290

> Zwirglmaier K, Jardillier L, Ostrowski M, Mazard S and others (2008) Global phylogeography of marine Synechococcus and Prochlorococcus reveals a distinct partitioning of lineages among oceanic biomes. Environ Microbiol 10: 147-161

Submitted: July 29, 2010; Accepted: January 9, 2011 Proofs received from author(s): March 15, 2011 